4th International Scientific Conference SEC-IASR 2019, Galati, Romania, 7th - 8th June, 2019

\title{
An Integrative Approach to Teaching Continuous and Perfect Tenses in English
}

\author{
Antoanela Marta MARDAR \\ https://doi.org/10.18662/lumproc/sec-iasr2019/21
}

How to cite: Mardar, A.M. (2020). An Integrative Approach to Teaching Continuous and Perfect Tenses in English. In S. Marin \& P. Moisescu (vol. eds.), Lumen Proceedings: Vol. 12. 4th International Scientific Conference SEC-IASR 2019 (pp. 199-208). Iasi, Romania: LUMEN Publishing House.

https://doi.org/10.18662/lumproc/sec-iasr2019/21 



\title{
An Integrative Approach to Teaching Continuous and Perfect Tenses in English
}

\author{
Antoanela Marta MARDAR ${ }^{1}$
}

Abstract

The appropriate use of tenses in English is agreed to be one of the most problematic aspects with which Romanian speakers of English have to cope when trying to communicate correctly and effectively in this language. Some problems are related to formal aspects, i.e. to aspects which imply combining the grammatically correct forms of the elements making up tenses in English (auxiliary and main verbs). Nevertheless, not few are the problems related to semantic and stylistic aspects, i.e. to aspects which condition tense choices depending on the types of actions to be expressed and on the speakers' need to stylistically mark the messages conveyed (modality).

When teaching tenses in the continuous and perfect aspects in English, the two types of problems mentioned above may be avoided if the formal and semantic matrixes specific to these tenses are used. Some might argue that young and teenage learners of English are likely find such formal and semantic matrixes rather abstract and might be unable to further apply them in similar contexts. Nonetheless, the present paper will demonstrate that a gradual and adapted approach to the formal and semantic aspects obviously shared by the continuous and perfect tenses in English may prove useful and effective, irrespective of the students' age and level of linguistic competence. Once understood and extensively practised, the two matrixes need to be appropriately evaluated in order to ensure long-term results.

Keywords: Aspect; duration; progress; temporariness; result.

1 “Dunarea de Jos” University of Galati, Romania, Antoanela.Mardar@ugal.ro 
Antoanela Marta MARDAR | Lumen Proceedings 12 | SEC-IASR 2019

\section{Introduction}

Teaching foreign languages to philology students in an ever changing academic environment which aims at adapting the relevant theoretical notions to be taught to the practical requirements of a global labour market, challenges the academics directly involved in the teaching process to consider innovative and more practical approaches which may help students understand the new theoretical notions more easily and subsequently apply these notions correctly, irrespective of the field of activity they might choose after graduation.

Bearing these aspects in mind, the present paper aims at suggesting a practical formula which may be used, with a significant rate of success, in teaching continuous and perfect tenses in English to undergraduate philology students, in particular.

\section{Theoretical Background}

Continuous and perfect tenses in English are directly correlated to the verb category of aspect which is marked both formally and semantically in all the corresponding tenses, whether considering finite or non-finite forms of the verb. The formal presence of the auxiliary verbs to be and to bave as marks of the continuous and perfect aspect, respectively, is doubled by the existence of a series of common semantic features traceable in symmetric contexts in which continuous and perfect tenses are used.

As stated in a previous article [6], the formal mark of the continuous or progressive aspect in English, i.e. the auxiliary verb to be, is an obligatory element found in all the corresponding tenses (e.g. Present Tense Continuous, Past Tense Continuous, Future Tense Continuous, Future-inthe Past Continuous, the Continuous Present Conditional, the Continuous Present Subjunctive, the Continuous Past Subjunctive, and the Continuous Present Infinitive) which always requires the present participle of the main/ lexical/ notional/full meaning verb. Similarly, the auxiliary verb to have, which is a formal mark of the perfect or perfective aspect in English, is traceable in all the corresponding perfect tenses (e.g. Present Perfect Simple, Past Perfect Simple, Future Perfect Simple, Future Perfect-in-the-Past Simple, the Simple Perfect Conditional, the Simple Perfect Subjunctive, the Simple Perfect Infinitive and Perfect Gerund) and is always combined with the past participle of the main verb. (See Table 1) 
Antoanela Marta MARDAR | Lumen Proceedings 12 | SEC-IASR 2019

Table 1. Formal marks of the continuous and perfect tenses in English

\begin{tabular}{ccc}
\hline ASPECT / TENSE & $\begin{array}{c}\text { CONTINUOUS/ } \\
\text { PROGRESSIVE }\end{array}$ & $\begin{array}{c}\text { PERFECT/ } \\
\text { PERFECTIVE }\end{array}$ \\
\hline FORMAL MARKS & $\begin{array}{c}\text { aux. to be }+ \text { the present } \\
\text { participle of the main verb }\end{array}$ & $\begin{array}{c}\text { aux. to bave }+ \text { the past } \\
\text { participle of the main verb }\end{array}$
\end{tabular}

The continuous and the perfective aspects coexist a series of verb forms in English which bring together, as their names suggest, the auxiliary verbs to be and to have: Present Perfect Continuous, Past Perfect Continuous, Future Perfect Continuous, Future Perfect-in-the-Past Continuous, the Continuous Perfect Conditional, the Continuous Perfect Subjunctive and the Continuous Perfect Infinitive. In the case of such aspectual combinations, the auxiliary verb to have, used in the tenses it marks, is followed by the past participle of the auxiliary verb to be, which further requires the present participle of the main verb.

As far the semantic features shared by continuous and perfect tenses in English are concerned, the continuous aspect is commonly used in English in order to express actions in full progress, durative actions or temporary actions/situations, being frequently associated with changing situations and with modality (the speakers' attitude towards the message conveyed), as well [2], [3]. On the other hand, the perfect aspect,as illustrated by all perfect tenses in English, is selected when reference needs to be made to past completed actions, situations or events. (SeeTable 2)

Table 2.Semantic marks of the continuous and perfect tenses in English

\begin{tabular}{ccc}
\hline $\begin{array}{c}\text { ASPECT/ } \\
\text { TENSE }\end{array}$ & $\begin{array}{c}\text { CONTINUOUS/ } \\
\text { PROGRESSIVE }\end{array}$ & $\begin{array}{c}\text { PERFECT/ } \\
\text { PERFECTIVE }\end{array}$ \\
\hline $\begin{array}{c}\text { SEMANTIC } \\
\text { MARKS }\end{array}$ & $\begin{array}{c}\text { actions in full progress; } \\
\text { durative actions; } \\
\text { temporary actions; } \\
\text { changing situations; } \\
\text { modality. }\end{array}$ & $\begin{array}{c}\text { past completed actions, } \\
\text { situations or events. }\end{array}$ \\
\end{tabular}

Despite the fact that continuous and perfect tenses in English obviously share a relevant number of formal and semantic features, there are hardly any theoretical and practical approaches to these tenses designed according to the corresponding formal and semantic matrixes characterising them. Under the circumstances, an integrated formal and semantic approach to 
teaching, practicing and evaluating continuous and perfect tenses in English might prove not only more accessible, but also very useful. Once the common formal and semantic aspects of the English tenses are clearly explained and thoroughly practiced, the students' understanding of the tense-aspect related notions may be significantly facilitated and their ability to apply and integrate the theoretical notions regarding continuous and perfect tenses in various symmetrical contexts may be significantly improved.

\section{Argument of the paper}

Although teaching English as a foreign language implies approaching numerous grammar notions, which are often regarded as abstract and difficult to understand by Romanian students, most Romanian teachers of English will probably agree that verb tenses represent the most common source of grammar errors made by Romanian students, irrespective of their age and level of linguistic competence.

Many of these errors are related to the form that English verbs have for the various moods and their corresponding tenses, but the most difficult choices that Romanian students have to make when communicating in English originate in the uses and meanings of tenses and in their possible semantic and stylistic interpretations. In the latter case, numerous students probably experience difficulties related to tense choice because they seek to mechanically learn and use English tenses without understanding the logical relationship between the grammatical notion of tense and the three main coordinates of the physical time, i.e. past, present and future, to which they implicitly relate when communicating in any language.

In an attempt to gradually move from traditional to modern approaches used in teaching grammar, English and Romanian authors of English grammars have constantly adapted their presentations of the theoretical notions and the structure of the exercises to be used for the students' practice and evaluation. Nevertheless, the results visible in the students' level of linguistic competence are not always as good as expected, numerous Romanian learners of English being overwhelmed by the seemingly abstract tense-related theoretical notions and confused by the lack of correlation existing between them.

As regards the practical part, the students' contextual choices of tenses are most often correct when supported by a series of accessible and relevant elements (e.g. specific time indicators, verbs not normally used in the continuous aspect) and incorrect when, for instance, time indicators traditionally associated with certain tenses and specific time reference are 
combined with other tenses and a different time reference. A relevant example in this respect is the adverb today, which is traditionally associated with Present Tense Continuous and with present reference, but which may also be used with Past Tense Simple for past reference, with Present Tense Continuous for future reference and with Present Perfect Simple for actions combining past and present time reference:

e.g. I am not working today. (temporary present state of affairs only today - present reference)

I didn't work today (at the end of the working day) (past reference - past completed action - nothing can be changed any more)

I am meeting Jake today. (later today as compared to the moment of speaking - future reference - future arrangement) I haven't worked today. (past and present reference - from the beginning of today up to the present, but the working day is not over.)

Having walked in my students' shoes myself, I have been trying, as a teacher, to identify and logically group common formal and semantic aspects specific to English tenses so as to reduce the burden of theoretical notions to be assimilated and to encourage them to make logical connections between various tenses in English. In the teaching process, special attention has also been paid to relevant stylistic differences in terms of register and variety of English, but these aspects will not be dealt with in the present paper.

Regarding the common formal and semantic aspects specific to the various English tenses, reference will be made strictly to continuous and perfect tenses of the Indicative Mood which are highly illustrative for the assumption that an integrative and logically structured approach to teaching such tenses in English is much more practical than those suggested by traditional grammars of English.

\section{Arguments to support the thesis}

Starting from a dictionary definition which states that if two or more things integrate or are integrated, they combine or work together in a way that makes something more effective (https://www.ldoceonline.com/dictionary/ integrate) an integrative approach to teaching continuous and perfect tenses in English implies, in the present view, combining the formal and semantic characteristics specific to each of the two corresponding aspects and drawing relevant parallels between various moods and tenses. 
The existence of formal and semantic matrixes which are shared by most tenses in English has been pointed out by other specialists in the field [1], [4] and has been exploited and enlarged on in a series of articles [5], [6], [7], [8], as well. Although seemingly difficult to identify and apply by nonnative speakers of English, these matrixes are very practical and they may significantly simplify the teaching and evaluation processes for teachers and the learning process for students, irrespective of their age group and of their level of linguistic competence.

The formal symmetry existing in the case of all continuous and perfect tenses may be initially tested on the tenses of individual moods, and, in a subsequent stage, on the tenses of two, three, four or five moods, respectively. To be more explicit, teachers may start from the continuous and perfect tenses of the Indicative mood and then gradually move to the tenses of the Conditional, Subjunctive, Infinitive and Participle. Moreover, the numerous continuous and perfect tenses corresponding to the moods mentioned above may grouped in the presentation and practice stages according to whether the corresponding verb forms are finite or non-finite (e.g. 1. finite forms of the verb: Indicative, Conditional, Subjunctive; 2. Nonfinite forms of the verb: Infinitive and Participle)

As regards a possible integrative approach to teaching the semantic features shared by continuous and perfect tenses in English, such an approach would imply an initial selection of types of actions commonly expressed by the two types of tenses envisaged (actions in progress, durative actions, temporary actions/situations; past completed actions) and a further logical and well-structured presentation designed so as to help students understand that different tenses may express the same types of actions, but placed on different points on the axis of the physical time.

Combining the formal and semantic aspects mentioned above, an integrative approach to teaching continuous and perfect tenses in English would imply understanding and memorising a small number of grammatical formulae which will minimally change according to the temporal reference (present, past, future, etc.) envisaged by students in their communication.

\section{Arguments to argue the thesis}

Some might consider that an integrative approach to teaching continuous and perfect tenses in English is unlikely to prove accessible and useful to young learners of English. Indeed young learners of English are unlikely to identify the formal and semantic matrixes of English tenses by themselves, and even when these two matrixes are clearly explained and 
extensively practiced, students may still find it difficult to apply them correctly to all tenses. The same holds valid in the case of teenagers who, despite having more experience and more practice in English, lack the ability to synthesize information and to make logical connections.

Adult learners, on the other hand, will have the necessary life experience and ability to synthesize information, but they will most often lack practice and confidence to communicate in English.

\section{Dismantling the arguments against}

The idea that an integrative approach to teaching continuous tenses is unlikely to have good results with young, teenage and adult learners, may be easily contradicted by the examples below:

e.g. He is reading an interesting book right now/ this week. (present time reference- an action which is in full progress at the moment of speaking/ at present)

He was reading an interesting book this time last night. past time reference- an action which was in full progress at a given moment in the past)

He will be reading an interesting book this time tomorrow morning/ next week.(future time reference- an action which will be in full progress at a given moment in the future/ within a future interval)

Present Tense Continuous, Past Tense Continuous and Future Tense Continuous are illustrative for both the formal and semantic matrixes characterizing continuous tenses. Formally speaking, these tenses are marked by the presence of the auxiliary verb to be, which provides relevant information about the specific verb categories (voice, mood, tense, person and number), about the time reference (present, past, future) and about the doer(s) of the action. From a semantic point of view, the three tenses express the same type of action, i.e. action in progress/full development, the only obvious difference being the placement of the actions on the axis of time, thus their time reference.

If teaching continuous tenses in English starts from the 3 tenses corresponding to the three main points on the axis of time and from their most common grammatical use (i.e. action in full progress), their formal and semantic features may be easily understood and further applied in similar contexts. The age group is relevant, up to a point, but the level of linguistic competence in both English, as a foreign language, and Romanian, as the students' native language, is surely more relevant for the extent to which 
these formal and semantic matrixes may be understood and correctly used by Romanian speakers of English.

Such a demonstration is valid in the case of perfect tenses which may also be taught by using an integrative formal and semantic approach. Let us consider the sentences below:

e.g. He has read an interesting book. (past + present time referencean action which was completed in the past but has a present result or consequence)

He had read that interesting book before his father returned from the voyage. past $1+$ past 2 time reference- an action which was completed before another past action, in an earlier past, and had a result/ consequence in a later past)

He will have read this book by tomorrow/next week. (past + future time reference- an action which will be completed before another future moment/ interval)

Present Perfect Simple, Past Perfect Simple and Future Perfect Simple are all perfect tenses formally marked by the presence of the auxiliary verb to have which requires the past participle of the immediately following (main) verb. Similarly to the auxiliary verb to be, the auxiliary to have is used in the corresponding tense it marks. As regards the semantic value shared by the three perfect tenses, they all express completed actions and integrate the idea of some past reference.

Last, but not least, those tenses of the Indicative Mood which combine the continuous aspect with the perfective one, are illustrative for the ways in which the specific formal and semantic aspects coexisting in these perfect-continuous tenses may be blended in an integrative teaching approach:

e.g. He has been reading for over two hours. (past + present time reference- an action which started in the past (over two hours ago, which has been in full progress - and durativefor over 2 hours till now)

He had been reading for over two hours before his father returned from work. (past 1 + past 2 time reference- an action which started in an earlier past and which was in progress and durative up to another (later) past moment)

He will have been reading for over 2 hours by 9 p.m. (past + future time reference - a future action in progress and durative which will be completed before another future moment)

Even though not enlarged on in the present paper, the Conditional, Subjunctive, Infinitive and Participle moods may equally support the idea of an integrative approach to be used in teaching continuous and perfect tenses 
[5], [6], [7], [8]. Moreover, creative teachers may further exploit the use of these two aspects taken separately or combined to demonstrate that certain moods (the Indicative, Conditional and Subjunctive, in particular) may be selected when students want to stylistically mark their communication in English (i.e. to express modality: irritation, annoyance, admiration, suggestion, reproach, wish, regret, etc.)

\section{Conclusions}

The aspects approached and demonstrated in the present paper support the idea that an integrative formal, semantic and stylistic approach may be used in teaching continuous and perfect tenses in English, irrespective of the students' age and level of linguistic competence in this language. Teachers have the most difficult task in the teaching - learning process. They are supposed to initially structure the theoretical aspects and to support them with relevant examples. In the practice stage they are expected to select relevant exercises meant to facilitate the students' understanding of the theoretical aspects synthesized and their further integration in similar communicative contexts. The evaluation stage is very important, as well, as it may give teachers useful information about the more problematic aspects which prevented students from fully understanding and correctly applying the notions introduced.

\section{References}

[1] Celce-Murcia M, Larsen-Freeman D. The Grammar Book. An ESL/EFL Teacher's Course. USA: Heinle and Heinle; 1999.

[2] Croitoru E. Modals. Tenses. Aspect. Galati: "Dunarea de Jos" University of Galati Foundation; 2002.

[3] Croitoru E. Mood and Modality. Iasi: Institutul European; 2002.

[4] Lewis M.The English Verb. An Exploration of Structure and Meaning. UK: Thomson Heinle; 2002.

[5] MardarAM.On the Practicality of Using Formal and Semantic Matrixes in Teaching English Tenses. LTRQ.2018; (6): 31-39.

[6] Mardar AM. A Comparative - Contrastive Approach to Auxiliary Verbs in English, Romanian and Italian. "Dunărea de Jos"University of Galati Annals, Fascicle XXIV General Lexis/ Specialized Lexis. Cluj-Napoca: Casa Cărții de Ştiință 2018; year XI. No. 1-2 (19-20): 156-164.

[7] Mardar AM. On the Usefulness of Using Formal and Semantic Similarities in Teaching English and Italian Hypothetical Constructions.The Annals of "Ovidius" University of Constanta: Philology Series. 2019. 30(1): 115-126. 
Antoanela Marta MARDAR | Lumen Proceedings 12 | SEC-IASR 2019

[8] Mardar I. Exploring the Matrix of the English Tenses in Classroom in TranslationStudies: Retrospective and Prospective Views Galati: Galati University Press; 2008. pp. 174-184. 